\title{
Electrochemical performance of $\mathrm{rGO} / \mathrm{NiCo}_{2} \mathrm{O}_{4} @ \mathrm{ZnCo}_{2} \mathrm{O}_{4}$ ternary composite material and the fabrication of an all-solid-state supercapacitor device
}

\section{Supporting information}

\section{Experimental procedure}

\section{Synthesis of rGO}

Modified Hummers and Offerman's method were followed to synthesize the reduced graphene oxide. $2 \mathrm{~g}$ of graphite powder was dissolved in $100 \mathrm{~mL}$ of concentrated $\mathrm{H}_{2} \mathrm{SO}_{4}$ and the mixed solution was stirred continuously for $1 \mathrm{~h}$ in an ice bath. $8 \mathrm{~g}$ of $\mathrm{KMnO}_{4}$ was added slowly in the above solution and the temperature of the solution was maintained at $10{ }^{\circ} \mathrm{C}$. After 30 min the cooling ice bath was removed, and $100 \mathrm{~mL}$ of DD water was added into the solution. The mixed solution was stirred at room temperature for another $1 \mathrm{~h}$. Then, $300 \mathrm{~mL}$ of DD water and $20 \mathrm{~mL}$ of hydrogen peroxide $\left(\mathrm{H}_{2} \mathrm{O}_{2}\right)$ was added for reducing the residual $\mathrm{KMnO}_{4}$ presented in the solution. Finally, the unwanted metal ions were removed by using $5 \%$ of aqueous $\mathrm{HCl}$ solution. After removing the metal ions, the solution was washed with DD water several times until the complete solution reached a $\mathrm{pH}$ of 6 . The precipitate was collected and dried at $50{ }^{\circ} \mathrm{C}$ for $24 \mathrm{~h}$, and the dried powder was known as graphene oxide. 1.0 $\mathrm{g}$ of graphene oxide was dispersed into $500 \mathrm{~mL}$ of DD water using ultrasonication in $5 \mathrm{~h}$ to remove unexfoliated graphene oxide. The final residue was dried at $50{ }^{\circ} \mathrm{C}$ for $24 \mathrm{~h}$, the exfoliated graphene oxide was formed. $500 \mathrm{~mL}$ of DD water was poured into the $300 \mathrm{mg}$ of exfoliated graphene oxide (XGO). The solution was kept in an oil bath under $95{ }^{\circ} \mathrm{C}$ and continuously stirred for $72 \mathrm{~h}$. The reduction of exfoliated graphene oxide was obtained. After reaching the room temperature, the residue was collected, washed and dried. Finally, reduced graphene oxide (rGO) nanosheets were obtained. [1,2]

\section{Synthesis of $\mathrm{ZnCo}_{2} \mathrm{O}_{4}$ nanomaterial}


$0.1 \mathrm{M}$ of $\mathrm{Zn}\left(\mathrm{NO}_{3}\right)_{2} \cdot 6 \mathrm{H}_{2} \mathrm{O}$ and $0.2 \mathrm{M}$ of $\mathrm{Co}\left(\mathrm{NO}_{3}\right)_{2} \cdot 6 \mathrm{H}_{2} \mathrm{O}$ were dissolved in $40 \mathrm{~mL}$ of DD water. Subsequently, 0.5 M of urea and 0.6 M of ethylene glycol (EG) were added to the solution. The mixed solution was stirred for $4 \mathrm{~h}$. Then the solution was transferred to $50 \mathrm{~mL}$ Teflon lined stainless steel autoclave and maintained the temperature at $120{ }^{\circ} \mathrm{C}$ for $16 \mathrm{~h}$. After cooled down to room temperature, the precipitate was collected, washed, and dried at $60{ }^{\circ} \mathrm{C}$. The dried as-prepared $\mathrm{ZnCo}_{2} \mathrm{O}_{4}$ was used to fabricate the $\mathrm{rGO} / \mathrm{NiCo}_{2} \mathrm{O}_{4} @ \mathrm{ZnCo}_{2} \mathrm{O}_{4}$ nanocomposite material.[3]

\section{Synthesis of rGO/NiCo2 $\mathrm{O}_{4} @ \mathrm{ZnCo}_{2} \mathrm{O}_{4}$ nanocomposite}

$0.1 \mathrm{M}$ of $\mathrm{Co}\left(\mathrm{NO}_{3}\right)_{2} \cdot 6 \mathrm{H}_{2} \mathrm{O}$ and $0.05 \mathrm{M}$ of $\mathrm{Ni}\left(\mathrm{NO}_{3}\right)_{2} \cdot 6 \mathrm{H}_{2} \mathrm{O}$ were dissolved in $20 \mathrm{~mL}$ of DD water. Then, $0.25 \mathrm{M}$ of urea and $0.3 \mathrm{M}$ of ethylene glycol were added into the solution and stirring for $1 \mathrm{~h}$. The completely mixed solution was named as Sol A. $60 \mathrm{mg}$ of as-prepared $\mathrm{ZnCo}_{2} \mathrm{O}_{4}$ was homogeneously dispersed in the $10 \mathrm{~mL}$ of DD water using ultrasonicator. Then, the $\mathrm{ZnCo}_{2} \mathrm{O}_{4}$ dispersed solution was poured into the above solution and it was named as Sol B. Finally, $5 \mathrm{mg}$ of rGO was homogenously dispersed in $10 \mathrm{~mL}$ of DD water using ultrasonicator and transferred into Sol B. The completely mixed solution was stirred for

another $4 \mathrm{~h}$, then transferred into the autoclave and kept at $120^{\circ} \mathrm{C}$ for $12 \mathrm{~h}$. The as-prepared material was annealed at $350{ }^{\circ} \mathrm{C}$ for $2 \mathrm{~h}$ in an open-air atmosphere. Finally, $\mathrm{rGO} / \mathrm{NiCo}_{2} \mathrm{O}_{4} @ \mathrm{ZnCo}_{2} \mathrm{O}_{4}$ ternary composite material was obtained. Four sets of samples were prepared by varying the concentration of rGO such as $5 \mathrm{mg}(0.3 \mathrm{wt} \%), 10 \mathrm{mg}(0.6 \mathrm{wt} \%), 50$ $\mathrm{mg}$ (3 wt\%), and $100 \mathrm{mg}(6 \mathrm{wt} \%)$ and it was named as RNZC1, RNZC2, RNZC3, and RNZC4 respectively.

\section{Material Characterization}

Structural formation and phase purity of the nanomaterial were determined using Rigaku Ultima III powder X-ray diffractometer (XRD). The existence of a functional group 
in the nanomaterial was identified using Thermo-scientific NICOLET iS5 Fourier transform infrared spectrometer (FTIR). The surface morphology of the materials was recorded using ZEISS field emission scanning electron microscopy (FESEM) and Tecnai G2, 20 Twin Transmission electron microscopy (HRTEM). Brucker Quantax 200 AS energy dispersive Xray analysis (EDX) spectrum was used to analyze the presence of elemental composition in the nanomaterial. Surface chemical analysis of the composite material was analyzed using multiprobe photoelectron spectroscopy with Al Ka source (Omicron Nanotechnology).

The electrochemical property of the material has been investigated using SP-150 BioLogic electrochemical workstation. Cyclic voltammetry (CV) and charge/discharge techniques $(\mathrm{CHDH})$ and electrochemical impedance spectroscopic studies (EIS) were used to find out the supercapacitive behavior of the material. EIS was measured within the frequency range of 0.01 to $100 \mathrm{kHz}$ with a sinusoidal signal amplitude is $4 \mathrm{mV}$. Binder and the additivefree active material was used as a working electrode material. $100 \mu \mathrm{L}$ of DMF $(\mathrm{N}, \mathrm{N}-$ Dimethylformamide) solution was added into the electroactive material for making the uniform slurry, and it was coated on the $1 \times 1 \mathrm{~cm}^{2}$ area of the Ni-foam substrate. Active material coated on the Ni-foam current collector was dried at $60{ }^{\circ} \mathrm{C}$ for $5 \mathrm{~h}$, where the mass of the active electrode material loaded in the device is $1 \mathrm{mg} . \mathrm{Hg} / \mathrm{HgO}$ and the platinum electrode were used as a reference and counter electrode respectively. $2 \mathrm{M}$ aqueous $\mathrm{KOH}$ was used as an ionic conducting medium.

\section{Fabrication of all-solid-state symmetric/asymmetric supercapacitor device}

All-solid-state symmetric supercapacitor device was fabricated as follows: Prior to assembling the device, the gel electrolyte was synthesized by using $2 \mathrm{~g}$ of PVA and $2 \mathrm{M}$ $\mathrm{KOH}$ electrolyte solution. $20 \mathrm{~mL}$ of DD water was heated at $80{ }^{\circ} \mathrm{C} .2 \mathrm{~g}$ of PVA was added into the DD water, and stirred for $2 \mathrm{~h}$ to make homogeneous gel solution. Then $2 \mathrm{M} \mathrm{KOH}$ 
solution was added into the PVA gel and stirred continuously, until the solution becomes gel. Polyurethane foam was acted as a separator which was soaked in the PVA/KOH gel electrolyte solution and dried at $60{ }^{\circ} \mathrm{C}$ for $6 \mathrm{~h}$. The dried foam was used as a separator. RNZC3 coated Ni-foam substrate was used as both anode and cathode material. Then, the electrode materials were sandwiched together with the polyurethane foam, and tightly packed using cellophane tape. The assembled all-solid-state symmetric RNZC3//RNZC3 supercapacitor device is examined using CV and charge/discharge studies. Similarly, the asymmetric device was fabricated by RNZC3 and rGO electrode materials, where RNZC3 was used as a anode and rGO was used as a cathode material. Specific capacity, energy density (E), and power density $(\mathrm{P})$ values of the device were calculated using the formulae 13 respectively.

$$
\begin{aligned}
& C_{s}\left(\mathrm{C} \mathrm{g}^{-1}\right)=\frac{I \Delta t}{m}-\cdots--(1) \\
& E\left(\mathrm{~W} \mathrm{~h} \mathrm{~kg}^{-1}\right)=\frac{C V^{2}}{7.2}-\cdots---(2) \\
& P\left(\mathrm{~kW} \mathrm{~kg}^{-1}\right)=\frac{E}{t}
\end{aligned}
$$

where $\mathrm{C}\left(\mathrm{C} \mathrm{g} \mathrm{g}^{-1}\right)$ is the specific capacity of the device, $I$ is the discharge current, $\Delta t$ is the discharging time, $m$ is the total mass of the active material, and $\mathrm{V}$ is the potential applied for the device. The potential range $(\Delta \mathrm{V})$ of the symmetric and asymmetric device is $0-1.2 \mathrm{~V}$ and 0-1.4 V respectively. 

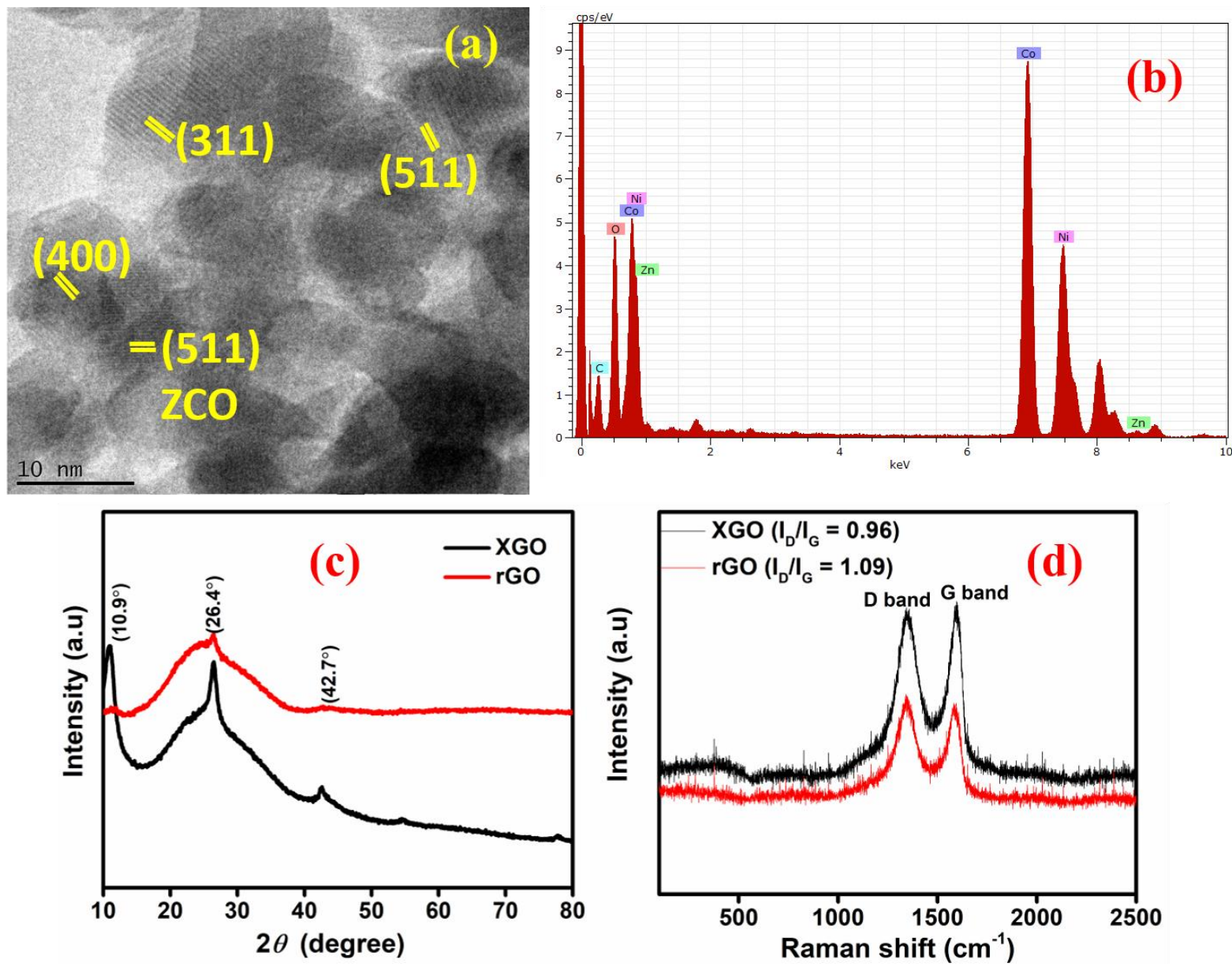

Figure S1: (a) HRTEM images of RNZC-3 composite material (b) EDX spectrum of RNZC3 ternary composite (c) XRD pattern of XGO and rGO (d) Raman spectra of XGO and rGO.

Lattice fringes obtained in the HR-TEM images (Fig.S1a) reveal the highly crystalline nature of the nanomaterial and the measured lattice spacing value is well-agreed with the standard JCPDS data. The inserted SAED pattern confirms the polycrystalline nature of the material. EDX spectrum in Fig.S1b proves the presence of $\mathrm{Ni}, \mathrm{Zn}, \mathrm{Co}, \mathrm{O}$, and $\mathrm{C}$ in the composite material. Very low intensity of $\mathrm{Zn}$ peak indicates the minimum amount of $\mathrm{Zn}$ presenting in the RNZC3 composite material. 

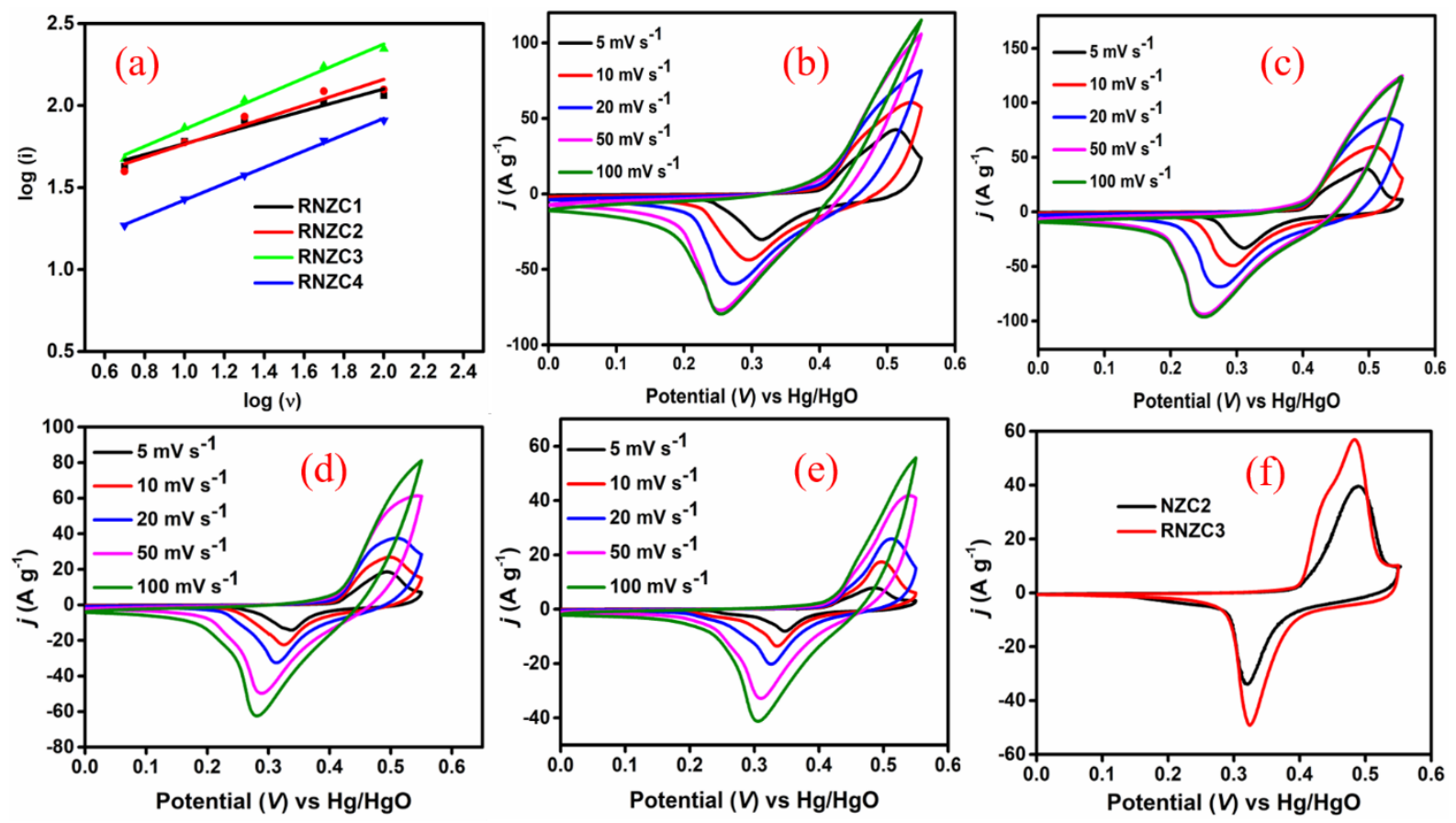

Figure S2: (a) Linear relation between anodic current and scan rate (b-d) CV curve of RNZC1, RNZC2, and RNZC4 composite materials respectively (e) CV curve of rGO comparative CV analysis of NZC2 (previously published material) and RNZC3 at a scan rate of $5 \mathrm{mV} \mathrm{s}^{-1}$.
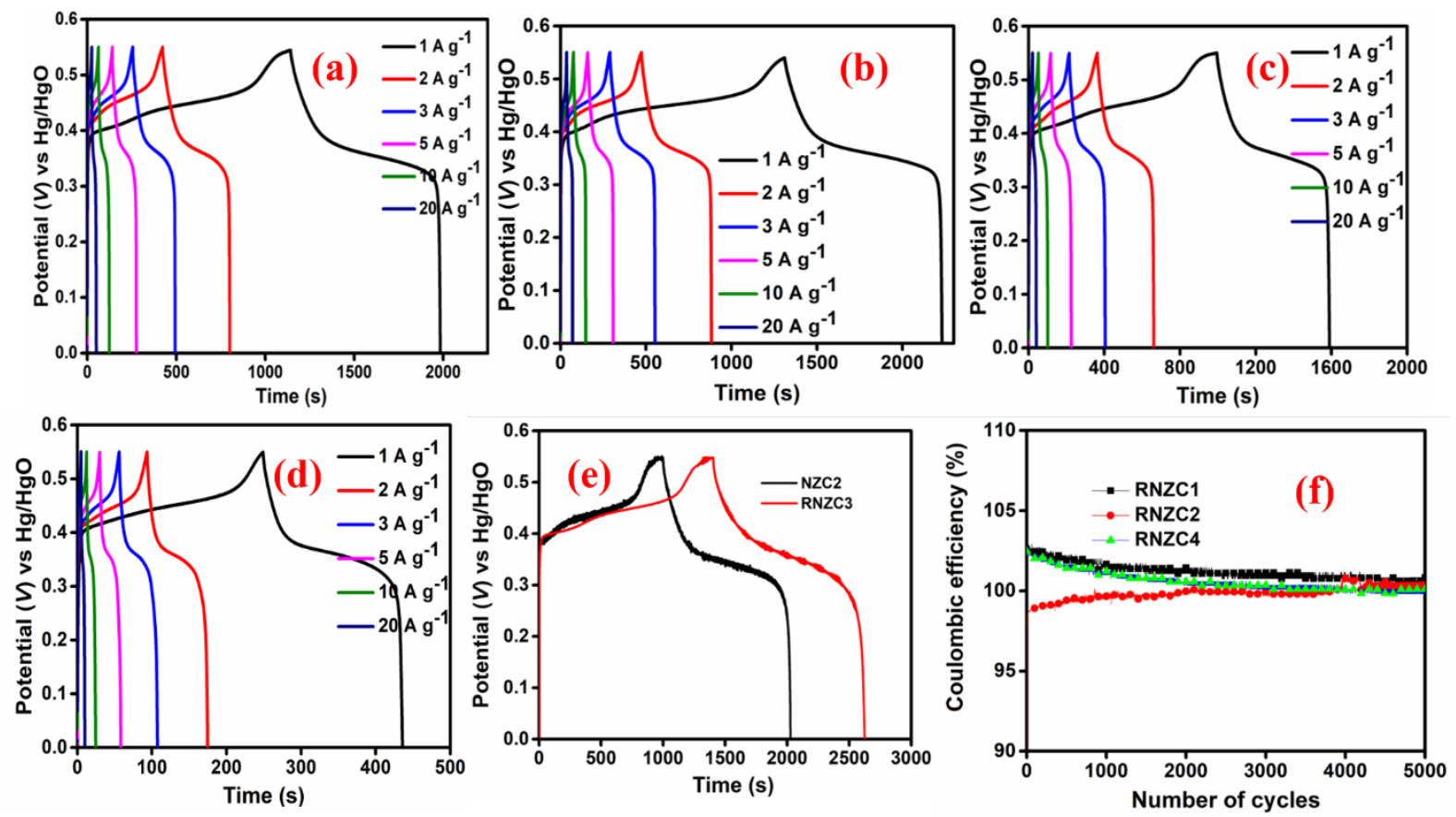
Figure S3: (a-c) charge/discharge studies RNZC1, RNZC2, and RNZC4 composite materials at different current densities, (d) charge/discharge study of rGO (e) comparative charge/discharge studies of NZC2 (previously published material) and RNZC3 at a current density of $1 \mathrm{~A} \mathrm{~g} \mathrm{~g}^{-1}$ (f) coulombic efficiency of the ternary composite material.

Charge/discharge studies of Fig.S3(a-c) is used to determine the specific capacity value of the RNZC1, RNZC2, and RNZC4 composite material. Specific capacitance value for RNZC1 is $847,756,717,676,611$, and $505 \mathrm{C} \mathrm{g-1}$ at a current density of $1,2,3,5,10$ and 20 $\mathrm{A} \mathrm{g}^{-1}$ respectively. RNZC2 reveals the specific capacitance of 928, 823, 796, 739, 721, and $690 \mathrm{C} \mathrm{g}^{-1}$ at a current density of 1, 2, 3, 5, 10 and $20 \mathrm{~A} \mathrm{~g}^{-1}$ respectively. RNZC4 obtained the capacitance value of $615,601,576,545,498$, and $405 \mathrm{C} \mathrm{g}^{-1}$ at a current density of $1,2,3,5$, 10 and $20 \mathrm{~A} \mathrm{~g} \mathrm{~g}^{-1}$ respectively. rGO nanosheets reveal the specific capacity value of 189,163 , $154,142,120,96 \mathrm{C} \mathrm{g}^{-1}$ at a current density of $1,2,3,5,10$ and $20 \mathrm{~A} \mathrm{~g}^{-1}$ respectively.
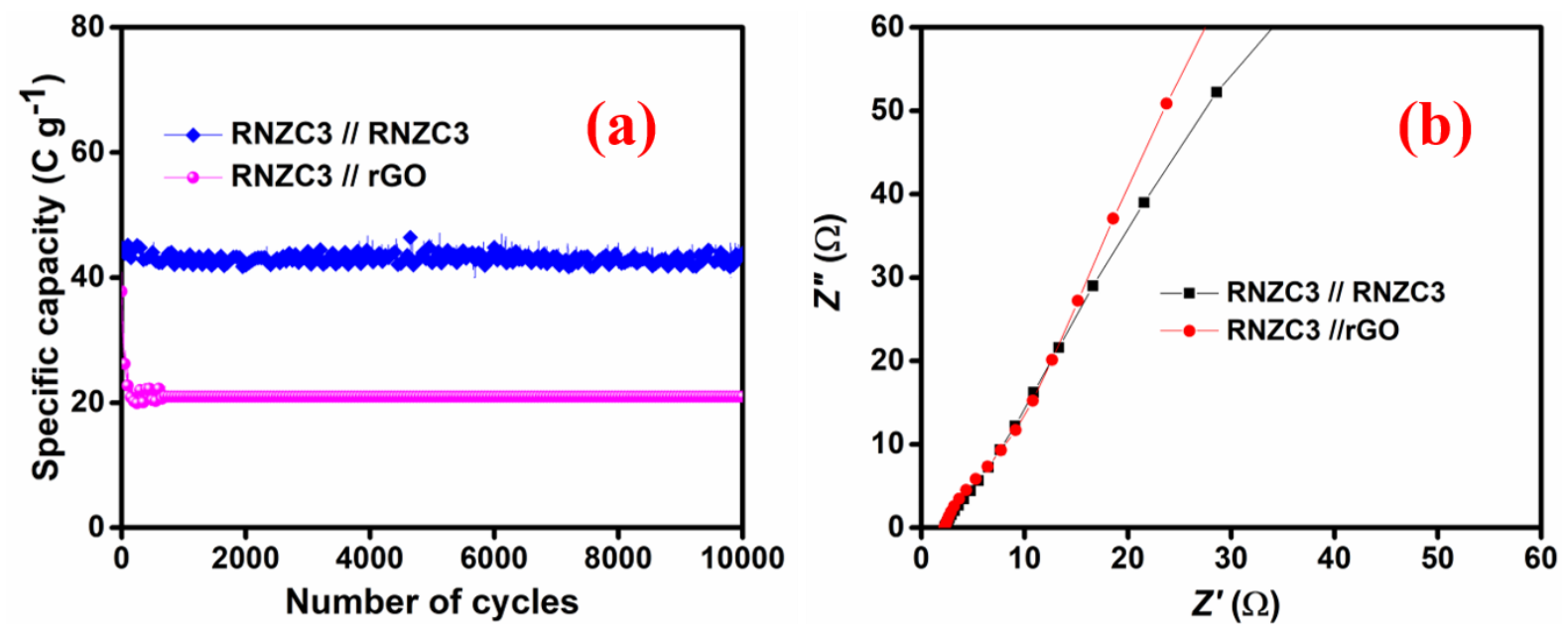

Figure S4: (a)Stability (b) EIS studies of RNZC3//RNZC3 and RNZC3//rGO devices

\begin{tabular}{|l|l|l|l|l|l|l|}
\hline Supercapacitor device & \multicolumn{6}{l}{ Specific capacity } \\
& current density $\left(\mathrm{A} \mathrm{g}^{-1}\right)$ & \\
& $\mathbf{1}$ & $\mathbf{2}$ & $\mathbf{3}$ & $\mathbf{4}$ & $\mathbf{5}$ & $\mathbf{6}$ \\
\hline RNZC3//RNZC3 & 311 & 156 & 138 & 80 & 70 & 36 \\
\hline RNZC3//rGO & 260 & 120 & 80.67 & 74.24 & 72 & 60 \\
\hline
\end{tabular}

Table S1: Specific capacity values of symmetric and asymmetric supercapacitor device. 


\section{References}

1. Loryuenyong V, Totepvimarn K, Eimburanapravat P, Boonchompoo W, Buasri A (2013) Preparation and characterization of reduced graphene oxide sheets via water-based exfoliation and reduction methods. Adv. Mater. Sci. Eng. 2013, 1-5.

2. Kumar NA, Gambarelli S, Duclairoir F, Bidan G, Dubois L(2013) Synthesis of high quality reduced graphene oxide nanosheets free of paramagnetic metallic impurities. J. Mater. Chem A 1, 2789-2794.

3. Mary A.J.C, Sathish C.I, Kumar P.S.M, Vinu A, Bose A.C (2020) Fabrication of hybrid supercapacitor device based on $\mathrm{NiCo}_{2} \mathrm{O}_{4} @ \mathrm{ZnCo}_{2} \mathrm{O}_{4}$ and the biomass-derived $\mathrm{N}$-doped activated carbon with a honeycomb structure. Electrochim. Acta 342,136062. 